\title{
The Use of Two Media of Instruction in Biology: A Quasi-Experimental Study
}

\author{
Jomell M. Santiago MSc. ${ }^{1 *}$, Eden S. David Ph.D. ${ }^{2}$
}

\author{
${ }^{1}$ Faculty member, Department of Laboratory High School, College of Education, Nueva Ecija University of Science and \\ Technology San Isidro Campus, San Isidro, Nueva Ecija, 3106 Philippines \\ email: jomellsantiago8854@gmail.com \\ ${ }^{2}$ Faculty member, Department of Biological Science, College of Arts and Science, Central Luzon State University, Science City \\ of Muñoz, Nueva Ecija, 3120 Philippines
}

\begin{abstract}
This paper determined the effectiveness of the two media of instruction, English and Filipino, in selected topics in Biology using quasi-experimental research. Two sections of Grade 8 students were the respondents of this study. The researchers found that the difference in scores of the two groups was statistically significant. Students who were subjected to English as a medium of instruction recorded a significantly higher posttest score than those students who were taught using Filipino. Thus, English as a medium of instruction is more effective in teaching selected topics in Biology.
\end{abstract}

Keywords- Academic performance, Biology, English, Filipino, medium of instruction.

\section{INTRODUCTION}

In the field of education, one of the important factors that should be given attention is the language or medium of instruction because it is one way to ensure the efficient and effective transmission of information during the learning process. The authors in [1] state that" language of instruction is a vehicle through which education is delivered. Through language, the process of teachinglearning process is possible."

The study conducted by the International Studies of Educational Achievements (ISEA) on science achievements among 10-year old students throughout the world cited by the author [2] showed that the Hungarians, Swedes, Japanese, Koreans, and Norwegians who were taught and learn Mathematics and Science in their national language, got the highest scores in the International Education Assessment Test. Unfortunately, the Philippines obtained the lowest mean score in Mathematics and Science achievements. The result of the study shows that Filipino children, who were taught Mathematics and Science in a foreign language, perform far below than the students of other countries.
The researchers in[3] "documented that teachers believe English-medium instruction to be a setback to students' academic success and students stated that they could not understand the subject matter when the lectures are in English." The authors in [4] found that "English-medium instruction had considerable negative effects on geography, science, and world history."In the same manner, reference [5]"found similar differences in economics, geography, history, physics, chemistry, biology, and mathematics." In addition, the result of the study by [6] "suggests that instruction in English significantly and negatively affects the academic success of the students."

According to[7], "the use of mother tongue, which refers to the Filipino language in the Philippines, by the teachers plays a crucial role in the learning of subjects which contributed immensely to the understanding of the students in their lesson." In addition, [8] said that "mother tongue education should be given importance in educational policies and children should be taught in a language they understand and the same language should be used in the classroom in the early six years of education."

In contrast, the disadvantage of using mother tongue in teaching science particularly Biology are it contains many technical terms in describing its concepts, principles and theories, and is, therefore, more susceptible to reading difficulties than other natural sciences [9]. The author in [10] state that "learners in private schools perform much better in Biology as compared with learners in public schools because learners in private schools had a better English proficiency."

It was observed that the preferred language use as a medium of instruction is also a factor since students often have a difficult time to understand the language used by the teacher as well as the language used in the learning material and examination [11 and 12].

Because of these reasons, the researchers ventured on quasiexperimental research to compare and find out the 
effectiveness of English and Filipino as media of instruction in teaching Grade 8 students of selected topics in Biology. The result may serve as a benchmark for the researchers to develop a plan of action that will help Grade 8 students with their existing problem in Biology.It is in this regard that this study finds meaning and significance.

\section{MATERIALS AND METHODS}

The study utilized Campbell and Stanley's quasiexperimental design of the non-equivalent pretest-posttest control group design [13 and 14]. According to the author [15], "quasi-experimental design was used to evaluate the effectiveness of an intervention when the intervention has been implemented."

The two sections of Grade 8 students were selected using purposive sampling. "Purposive sampling is a nonprobability sampling method and it occurs when elements selected for the sample are chosen by the judgment of the researcher" [16].

The researchers conducted the study in March 2018 at Juan R. Liwag Memorial High School, located at Barangay Bayanihan, Gapan City, Nueva Ecija, Philippines. Informed consent from parents and assent from the respondents were secured by the researchers before doing the experimental process for ethical considerations. The research instruments used were the pretest and posttest questionnaires. The statistical tools utilized in this study were frequency, percentage, weighted mean and independent sample t-test.

\section{RESULTS AND DISCUSSION}

\subsection{Academic Performance of the Respondents}

Before the experimentation, student respondents were given a pretest in Biology about Cell Division and Genetics.

Table.1: Pretest Results

\begin{tabular}{llccccc}
\hline \multirow{2}{*}{ Score } & \multicolumn{2}{c}{ Verbal Description } & \multicolumn{2}{c}{ English Group } & \multicolumn{2}{c}{ Filipino Group } \\
& & \multicolumn{1}{c}{ Frequency } & Percent & Frequency & Percent \\
\hline $\mathbf{0 ~ t o ~ 8}$ & Beginning (Did not Meet Expectations) & 1 & 1.6 & 10 & 15.2 \\
$\mathbf{9}$ to $\mathbf{1 6}$ & Developing & (Fairly Satisfactory) & 28 & 44.4 & 34 & 51.5 \\
$\mathbf{1 7}$ to $\mathbf{2 4}$ & Approaching Proficiency (Satisfactory) & 20 & 31.8 & 21 & 31.8 \\
$\mathbf{2 5}$ to $\mathbf{3 2}$ & Proficient (Very Satisfactory) & 13 & 20.6 & 1 & 1.5 \\
$\mathbf{3 3}$ to $\mathbf{4 0}$ & Advanced (Outstanding) & 1 & 1.6 & 0 & 0.0 \\
\hline Total & & $\mathbf{6 3}$ & $\mathbf{1 0 0 . 0}$ & $\mathbf{6 6}$ & $\mathbf{1 0 0 . 0}$ \\
\hline
\end{tabular}

Table (1) showed the academic performance of the two groups of respondents in their pretest. In the group who were taught in English, 28 (44.4\%) got scores ranging from 9 to 16 with a verbal description of Developing or Fairly Satisfactory. There were $20(31.8 \%)$ who got scores ranging from 17 to 24 with a verbal description of Approaching Proficiency or Satisfactory and $13(20.6 \%)$ got scores ranging from 25 to 32 with a verbal description Proficient or Very Satisfactory. Only $1(1.6 \%)$ got a score ranging from 33 to 40 with a verbal description of Advanced or Outstanding and was under Beginning or Did not Meet Expectations whose score ranged from 0 to 8.

Meanwhile, in the group who were exposed to Filipino as a medium of instruction, $34(51.5 \%)$ got scores ranging from
9 to 16 with a verbal description of Developing or Fairly Satisfactory. There were $21(31.8 \%)$ who got scores ranging from 17 to 24 with a verbal description of Approaching Proficiency or Satisfactory and $10(15.2 \%)$ got scores ranging from 0 to 8 with a verbal description Beginning or Did not Meet Expectations. Only 1 (1.5\%) student was under Proficient or Very Satisfactory whose score ranged from 25 to 32 and nobody reached the Advances or Outstanding level.

The result on both groups is related to the findings in [17], that Filipino students' academic performance in Biology which is under the subject of Science and Technology is weak.

Table.2: Posttest Results

\begin{tabular}{lllrrrr}
\hline \multicolumn{2}{c}{ Score } & \multicolumn{2}{c}{ Verbal Description } & \multicolumn{2}{c}{$\begin{array}{c}\text { English Group } \\
\text { Frequency }\end{array}$} & \multicolumn{2}{c}{ Filipino Group } \\
Percent & Frequency & Percent \\
\hline $\mathbf{0}$ to 8 & Beginning (Did not Meet Expectations) & 0 & 0.0 & 4 & 6.1 \\
$\mathbf{9}$ to $\mathbf{1 6}$ & Developing & (Fairly Satisfactory) & 18 & 28.6 & 25 & 37.9 \\
$\mathbf{1 7}$ to $\mathbf{2 4}$ & Approaching Proficiency (Satisfactory) & 13 & 20.6 & 18 & 27.3 \\
$\mathbf{2 5}$ to 32 & Proficient (Very Satisfactory) & 10 & 15.9 & 17 & 25.7
\end{tabular}




\begin{tabular}{llllllr}
\hline $\mathbf{3 3}$ to 40 & Advanced (Outstanding) & 22 & 34.9 & 2 & 3.0 \\
\hline Total & $\mathbf{6 3}$ & $\mathbf{1 0 0 . 0}$ & $\mathbf{6 6}$ & $\mathbf{1 0 0 . 0}$ & \\
\hline
\end{tabular}

Table (2) showed the academic performance of the two groups in their posttest. In the English group, there were 22 (34.9\%) respondents who earned scores ranging from 33 to 40 with a verbal description of Advanced or Outstanding. Eighteen $(28.6 \%)$ got scores ranging from 9 to 16 with a verbal description of Developing or Fairly Satisfactory, 13 (20.6\%) got scores ranging from 17 to 24 with a verbal description of Approaching Proficiency or Satisfactory and $10(15.9 \%)$ got scores ranging from 25 to 32 with a verbal description of Proficient or Very Satisfactory. Nobody was under Beginning or Did not Meet Expectation level.

On the other hand, in the Filipino group, 25 (37.9\%) got scores ranging from 9 to 16 with a verbal description of Developing or Fairly Satisfactory. There were 18 (27.3\%) who got scores ranging from 17 to 24 with a verbal description of Approaching Proficiency or Satisfactory and $17(25.7 \%)$ got scores ranging from 25 to 32 with a verbal description Proficient or Very Satisfactory. Four students were under Beginning or Did not Meet Expectations whore scores ranged from 0 to 8 and only two students were under Advanced or Outstanding level whose scores ranged from 33 to 40. This shows that the respondents in the English group after the use of English language as a medium of instruction in teaching Biology to learn betterthan of the respondents in the group where the Filipino language was used as a medium of instruction in teaching Biology.

The finding of the study contradicts the findings of the following authors [18], [19] and[20], [21] and [22]. According to them, the use of the English language would seriously affect and become a limiting factor for student learning, and learners encounter enormous problem learning Biology. However, according to the following authors [23] and [24], "science and mathematics are dynamic areas of knowledge in which all sorts of new discoveries and a large portion of information related to them are found in English and should be taught in English."

Table.3: t-test of the Pretest and Posttest Performances of the Two groups

\begin{tabular}{ccccc}
\hline \multirow{2}{*}{ Group } & \multicolumn{2}{c}{ Pretest } & \multicolumn{2}{c}{ Posttest } \\
\cline { 2 - 4 } & Mean & t-value & Mean & t-value \\
\hline English & 18.34 & 2.01 & 25.03 & 3.02 \\
\hline Filipino & 13.93 & & 18.72 & \\
\hline
\end{tabular}

Table (3) showed that the English group had higher pretest and posttest score. The statistical analysis revealed that the pretest and posttest scores between the two groups have significant differences. This meant that the performance of the respondents in the English group after the use of English language as a medium of instruction is greater than the performance of the respondents in the experimental group where the Filipino language was used as a medium of instruction.

The result of the study implies that the use of the English language as a medium of instruction is more effective than the Filipino language in teaching science. The author in [25] stated that it is based on the fact that the language of instruction plays a significant role in students' academic performance. The reason why the control group had a higher posttest score was that the medium of instruction use was English and the language used in Biology which is under the subject of science was English. Since scientific and technological development is mostly recorded in English language, according to authors [26] and [27], "one advantage of using English as a medium of instruction is the higher quality of support materials compared to those in www.ijaems.com local languages."“Textbooks, articles, support websites, practice questions are better in both quality and quantity in English than in any other language. "Therefore, it is a disadvantage for all who do not use the English language because they may not have access to the world's known scientific and technological discoveries that are predominantly written in English" [28].

According to [29], "teachers and students prefer the use of English as the medium of instruction. The teachers find English as a more comfortable language for explaining ideas and concept and a valuable tool to source information technology."The findings of the author in [30] showed that the students had better learning performances when English was used as a medium of instruction than Filipino in teaching Social Sciences. Because of this, it is more advantageous to use the English language in teaching Biology than any language.

\section{CONCLUSIONS AND RECOMMENDATIONS}

Innovative and successful teachers should have the knowledge and the sense of purpose that allows them to rise

Page | 113 
above casual or conventional approaches and to do things others cannot [31] as cited by [32].

The researchers, being innovative teachers ventured on different approaches in teaching selected Biology and found out that the academic performance of the respondents under the group who were taught in English had statistically higher mean posttest score from those students under the group who were taught in Filipino. Language then appeared to have an effect on the students' academic performance. Hence, English as a medium of instruction was more effective in teaching selected topics in Biology. However, since the study is only limited to five topics in Biology, this study must be replicated on a larger scale over a longer span of time in order to attain more defined results. The researchers suggested taking the whole grading period which means more topics will be added. The same study may be undertaken for the Grade 8 students of private schools, which this study fails to include. Likewise, teachers and professors may consider a game-based teachinglearning process [33] in Biology which was proven to help the students be engaged in lessons regardless of the language of instruction. Lastly, the use of English and Filipino language as media in constructing modules should be conducted in order to determine if the language will have an effect in the performance of the students if it used as supplementary material.

\section{ACKNOWLEDGMENTS}

The authors would like to express their gratitude to the Grade 8 students who served as their respondents and to Dr. Sofronio P. Kalaw, Dr. Leila M. Collantes, Dr. Regidor G. Gaboy, Dr. Angeles M. De Leon, Dr. Arneil G. Gabriel, Dr. Gener S. Subia, Dr. Lily G. Salangsang and Ms. Luisa P. Reyes for their significant suggestions and comments for the improvement of this study.

\section{REFERENCES}

[1] Zorro, I. and Baracaldo, D. A. (2006). Cross-Curricular and a Cross-Cultural Bridge in a Teacher Preparation program (Handouts). [Online] Available: in http://nation/ teleconference, org/resources/2006/Imelda_Zorro_Deisy_Baracaldo_A_ Cross Curricular_ant (May 23rd, 2016)

[2] Cortes, J.C. (2005). Basic Education: The Foundation of People Empowerment. Educators Congress: Baguio City.

[3] Kinyaduka, B. D., \& Kiwara, J. F. (2014). Language of instruction and its impact on quality of education in secondary schools: Experiences from Morogoro Region, Tanzania. Journal of Education and Practice, 4(9), 90-95.
[4] Marsh, H. W., Hau, K. T., \& Kong, C. K. (2000). Late immersion and language of instruction in Hong Kong high schools: Achievement growth in language and non-language subjects. Harvard Educational Review, 70, 302-346.

[5] Education Bureau. (2006). Further evaluation on the implementation of the MOI guidance for secondary schools, 2002-2004. Hong Kong: Government Printer.

[6] Civan, A., \& Coşkun, A. (2016). The effect of the medium of instruction language on the academic success of university students. Educational Sciences: Theory \& Practice, 16, 1981-2004.

[7] Acquah, S.,Eshun, S. E., \&Afful-Broni, A. (2014). Towards a more Effective Education in Ghana: Teachers Coping Strategies in Teaching Natural Science. Journal of Education and Curriculum Development Research, 2 (1), 81-92.

[8] UNESCO, Global Education Monitoring Report 2016.

[9] Lock, R \& Richardson, J 1995, 'The readability of selected A-level Biology examination papers,' Journal of Biological Education, vol. 27, no. 3, pp. 205-2012.

[10] Mohidiu, BHN 2008, Students achievement and language problems in learning Biology in English in Public and private schools, MED Thesis, University of Brunei Danssalam. Monsod, Wennie. English versus Mother Tongue as a Medium of Instruction. GMA News. March 2, 2009

[11] Dresher, R., (2005). Training in Mathematics Vocabulary Educational Research Bulletin. No. 13, pp. $201-204$

[12] Johnson, H.G., (2010). The effects of instruction in mathematical vocabulary upon problem-solving in mathematics. Journal at Educational Research.4:38(July 2010) $97-10$.

[13] Campbell, D. T., and Stanley, J. C. (1966). Experimental and Quasi-experimental Designs for Research, Chicago: Rand McNally.

[14] Campbell, D. T., \& Stanley, J. C. (1963). Experimental and quasi-experimental design for research. Hopewell, NJ: Houghton Mifflin Company.

[15] Shadish, W., Cook, T., \& Campbell, D. (2002). Experimental and quasi-experimental designs for generalized causal inference. Boston: Houghton Mifflin Company.

[16] Black, S. E., Devereux, P. J. and Salvanes, K. G. (2005), "The More the Merrier? The Effect of Family Size and Birth Order on Children's Education", Quarterly Journal of Economics, 120(2), 669-700.

[17] TIMMS, International Report on Achievement, Tims s.be.edu/tims s.html. 2008 
[18] Gatmaitan, R. S., (2012). The Comprehensibility of Chemistry reading materials in English and Filipino. Unpublished Master's Thesis, UP, Diliman, Quezon City

[19] Mohidiu, BHN 2008, Students achievement and language problems in learning Biology in English in Public and private schools, MED Thesis, University of Brunei Danssalam.

[20] Yong, BCS 2003, 'Language problems in the learning of Biology through the medium of English,' Journal of Applied Research in Education, Vol. 7, no. 1, pp. 97104.

[21] Dresher, R., (2005). Training in Mathematics Vocabulary Educational Research Bulletin. No. 13, pp. $201-204$

[22] Johnson, H.G.,(2010). The effects of instruction in mathematical vocabulary upon problem-solving in mathematics. Journal at Educational Research.4:38(July 2010)97-110.

[23] Che Wan Jasimah Wan Mohamed Radzi \& Norazmi Noor. (2005). The use of English in Science and Mathematics: Implementation and Challenges. Jurnal Pendidikan. 25:27-38.

[24] Pembina. (2009). Teacher Competence in Teaching and Learning Science and Mathematics use English language and its implications on the performance of the Students Human Capital Development. Executive Report of Pembina Study: End PPSMI. http:/arkibppsmi. blogspot.com/2009/05/Laporaneksekutif-kajian-pembina.html [20 Oktober 2010].

[25] Kagwesage, A. M. (2012). Higher education students' reflection on learning in times of academic language shift. International Journal for the Scholarship of Teaching and Learning, 6(2), 1-15.

[26] Ministry of Education. (2002a). English for Teaching Mathematics and Science (ETeMS) Facilitator's Notes. English Language Teaching Centre, Teacher Education Division

[27] Pembina. (2009). Teacher Competence in Teaching and Learning Science and Mathematics use English language and its implications on the performance of the Students Human Capital Development. Executive Report of Pembina Study: End PPSMI. http:/arkibppsmi. Blogspot.com/2009/05/Laporaneksekutif-kajian-pembina.html[20 Oktober 2010].

[28] Fakeye, D. and Ogunsiji, Y. "English language proficiency as a predictor of academic achievement among ELF students in Nigeria," Journal of Science Research, vol. 37, pp. 490-495, March 2009

[29] Amamio, L. (2000). Attitudes of students, teachers and parents of RVM schools in Metro Manila toward
English and Filipino as media of instruction, (Unpublished Thesis) presented to the UST Graduate School, Manila, Philippines

[30] Gorgonio, John Paul R. (2011). Use of Filipino and English in Social Studies Learning. A Master thesis from Cebu Normal University, Cebu City, Philippines presented by the researcher during 2nd International Conference on Multidisciplinary Research last October 21-22, 2011 at Bacolod City, Occidental Negros

[31] Boiser, D. (2000) Strategies for Teaching: A Modular Approach. Rex Book Store: C.M. Recto Avenue, Manila.

[32] Subia, G.S. (2018) Comprehensible Technique in Solving Consecutive Number Problems in Algebra. Journal of Applied Mathematics and Physics, 6, 447457. https://doi.org/10.4236/jamp.2018.63041

[33] Subia, G.S., Amaranto, J.L., Amaranto, J.C., Bustamante, J.Y. and Damaso, I.C. (2019) Chess and Mathematics Performance of College Players: An Exploratory Analysis. Open Access Library Journal, 6: e5195. https://doi.org/10.4236/oalib.1105195 